\title{
Isolation and identification of Asaia sp. in Anopheles spp. mosquitoes collected from Iranian malaria settings: steps toward applying paratransgenic tools against malaria
}

Abbas Rami ${ }^{\dagger}$, Abbasali Raz ${ }^{\dagger}$, Sedigheh Zakeri and Navid Dinparast Djadid ${ }^{*}$

\begin{abstract}
Background: In recent years, the genus Asaia (Rhodospirillales: Acetobacteraceae) has been isolated from different Anopheles species and presented as a promising tool to combat malaria. This bacterium has unique features such as presence in different organs of mosquitoes (midgut, salivary glands and reproductive organs) of female and male mosquitoes and vertical and horizontal transmission. These specifications lead to the possibility of introducing Asaia as a robust candidate for malaria vector control via paratransgenesis technology. Several studies have been performed on the microbiota of Anopheles mosquitoes (Diptera: Culicidae) in Iran and the Middle East to find a suitable candidate for controlling the malaria based on paratransgenesis approaches. The present study is the first report of isolation, biochemical and molecular characterization of the genus Asaia within five different Anopheles species which originated from different zoogeographical zones in the south, east, and north of Iran.

Methods: Mosquitoes originated from field-collected and laboratory-reared colonies of five Anopheles spp. Adult mosquitoes were anesthetized; their midguts were isolated by dissection, followed by grinding the midgut contents which were then cultured in enrichment broth media and later in $\mathrm{CaCO}_{3}$ agar plates separately. Morphological, biochemical and physiological characterization were carried out after the appearance of colonies. For molecular confirmation, selected colonies were cultured, their DNAs were extracted and PCR was performed on the 165 ribosomal RNA gene using specific newly designed primers.

Results: Morphological, biochemical, physiological and molecular results indicated that all isolates are members of the genus Asaia.

Conclusions: Contrary to previous opinions, our findings show that Asaia bacteria are present in both insectary-reared colonies and field-collected mosquitoes and can be isolated by simple and specific methods. Furthermore, with respect to the fact that we isolated Asaia within the different Anopheles specimens from distinct climatic and zoogeographical regions, it is promising and may be concluded that species of this genus can tolerate the complicated environmental conditions of the vector-borne diseases endemic regions. Therefore, it can be considered as a promising target in paratransgenesis and vector control programs. However, we suggest that introducing the new technologies such as next generation sequencing and robust in silico approaches may pave the way to find a unique biomarker for rapid and reliable differentiation of the Asaia species.
\end{abstract}

Keywords: Paratransgenesis, Asaia, Bacteria, Malaria, Vector-borne diseases, Vector control

\footnotetext{
* Correspondence: navidmvrg@gmail.com

${ }^{+}$Abbas Rami and Abbasali Raz contributed equally to this work.

Malaria and Vector Research Group (MVRG), Biotechnology Research Center

(BRC), Pasteur Institute of Iran, Tehran, Iran
}

(c) The Author(s). 2018 Open Access This article is distributed under the terms of the Creative Commons Attribution 4.0 International License (http://creativecommons.org/licenses/by/4.0/), which permits unrestricted use, distribution, and

reproduction in any medium, provided you give appropriate credit to the original author(s) and the source, provide a link to the Creative Commons license, and indicate if changes were made. The Creative Commons Public Domain Dedication waiver (http://creativecommons.org/publicdomain/zero/1.0/) applies to the data made available in this article, unless otherwise stated. 


\section{Background}

Malaria is considered as the most deadly parasitic communicable disease worldwide and the most important vector-borne disease in Iran. Furthermore, it is a major health challenge in northern and southern parts of Iran $[1,2]$. The WHO world malaria report in 2015 proclaimed 212 million cases of disease and 429,000 deaths worldwide in 2015 [3]. Widespread insecticide and drug resistance in mosquitos and parasites, respectively, and the lack of an effective malaria vaccine are the main obstacles to achieve the goals of global malaria eradication program $[4,5]$. It is obvious that new solutions and management strategies are required for a successful control of malaria disease [6]. To overcome the existing barriers, the WHO invited about 2500 scientists with distinct specialties in different scientific groups from all over the world to determine the drawbacks of the first global malaria eradication program and suggest their solutions to revise the existing program and achieve global malaria eradication by 2050 [6]. One of the scientific groups was related to the vector control. They believed that to support the efforts towards global malaria elimination and eradication, development of complementary vector control strategies are mandatory. Particularly, those that are less vulnerable to the current problem in vector control and insecticide resistance are mandatory and these strategies should be considered in the frontline of malaria vector control intervention approaches. Therefore, these scientists suggested that the main attempts in vector control should be focused on transgenesis and paratransgenesis approaches, and designing new and efficient insecticides with different effect mechanisms compared to previous ones [7].

The main goal of performing the vector control approaches is intervening the transmission of parasites through the mosquitoes [8]. This aim can be achieved by killing the mosquitoes with insecticides and affecting the fitness of mosquitoes or reducing the competency of the vector by presenting new effector molecules which consequently block the sexual parasite development. In recent years, transgenesis and paratransgenesis have been introduced as promising strategies which can be used as effective tools for controlling vector-borne diseases. Genetically modified mosquitoes that express anti-plasmodium effector molecules in their midguts have been introduced in recent years [9-12]. Although genetic modification of insects was a challenge in previous years, new approaches such as phi C31 and CRISPR/Cas9 have been recently introduced and have improved the efficacy of the process [13-16]. Nevertheless, creation of genetically modified insects needs advanced technology, special instruments and skills. In addition, this technology reduces the risks and concerns of gene flow from one mosquito population to another which can be possible in the future [8, 17]. Another interesting technique for delivering the effector molecules is the genetic engineering of symbiotic microorganisms of mosquitoes such as bacteria, fungi and viruses to present the interfering molecules which is also known as paratransgenesis [5, 18-24]. Several studies have been performed on identification and using competent microorganisms to combat against vector-borne diseases, especially against malaria [1, 2, 25-29].

Among the mentioned microorganisms, bacteria have specific advantages such as: simple isolation, growth in basic media, availability of genetic engineering methods and tools, rapid replication rate and relatively uncomplicated approaches compared to other candidate microorganisms. Therefore, bacteria have been on the frontline of attention for developing an effective paratransgenic tool against malaria from the creation of this concept. Engineered vector-associated bacteria could impose a pathogenic effect on their host, interfere with their reproduction and fitness or reduce their competency $[8,30]$. Asaia is a genus of bacteria with unique features which has been isolated and characterized from the malaria vectors. This bacterium was isolated from An. stephensi for the first time and genetically modified and labeled by green fluorescent protein by Favia et al. [7]. Consequently, it was revealed that the bacteria are localized in many organs such as the midgut, salivary glands, and the reproductive system of female and male Anopheles and can disperse between these organs through the hemolymph [8]. Furthermore, Favia et al. [8] demonstrated that Asaia can transmit to the next generation vertically. These special features are the main advantages of this bacterium and those have led to Asaia be considered as a versatile tool in paratransgenesis. According to the performed studies, the distribution of these bacteria in mosquito populations is performed through various mechanisms, including co-feeding, sexual mating and maternal transmission [31, 32]. Asaia can be cultivated and genetically modified in the laboratory and can also be recolonized in the new host [33]. Vertical transmission capability suggests that Asaia is able to establish stable associations across multiple generations. This bacterium can be cultivated in cell-free media and can be easily transformed with exogenous DNA [8]. In a previous study, we could not isolate Asaia from field-collected samples from the north and south regions of Iran. According to the aforementioned specifications of Asaia and its importance in paratransgenesis, we modified our previous methods and tried to isolate Asaia in normal flora of different species of Anopheles in different regions of Iran, including Mazandaran, Bandar-Abbas, Chabahar and Kazerun.

\section{Methods}

Field collection of Anopheles spp.

Mosquitoes which were used in this study, originated from field- and laboratory-reared colonies of adult Anopheles spp. Coastal, semi-mountainous, or hilly rural 
areas (Siaho area and Eslamabad) with many permanent and seasonal rivers are the most important urban and rural regions for catching Anopheles in north, south, and southeastern part of Iran. Therefore, these regions with a wide distribution were selected for sampling and specimens were collected from Mazandaran, Chabahar, Bandar-Abbas (Siaho area) and Kazerun (Eslamabad) districts (Table 1). Larvae were collected from larval habitats using the standard dipping technique (350 $\mathrm{ml}$ dipper) and adults were captured from human and animal refuges and human settlements by hand catch method using an aspirator. After sampling, the larva specimens were transferred alive to the National Insectarium of Malaria and Vector Research Group (MVRG) at the Pasteur Institute of Iran (Tehran). After maturation, their adults were identified to species level using the standard morphological key of Iranian anophelines to determine the species of all Anopheles samples [34].

\section{Dissection of mosquitoes, isolation and cultivation of microorganisms}

All adult mosquitoes were anesthetized by incubating them for $2 \mathrm{~min}$ at $-20{ }^{\circ} \mathrm{C}$. Before dissection, the surfaces of the samples were sterilized by soaking in $70 \%$ ethanol in $2 \mathrm{ml}$ micro-tubes and shaking for $5 \mathrm{~min}$. Dissection was accomplished in sterile conditions under a biological laminar flow hood (class-II). Each dissected midgut was transferred to a $1.5 \mathrm{ml}$ micro-tube; its contents were suspended in $1 \mathrm{ml}$ of sterile saline solution $(0.9 \% \mathrm{NaCl})$ and homogenized by an electrical homogenizer. Then, a $0.5 \mathrm{ml}$ aliquot of this suspension was inoculated into the handmade enrichment media [8]. A specific enrichment broth media was used for isolation of the acetic acid bacteria in this study comprising 2.2\% D-sorbitol, $0.5 \%$ peptone, $0.5 \%$ yeast extract (Merck, Darmstadt, Germany), 100 ppm cycloheximide and its $\mathrm{pH}$ was adjusted to 3.5 with hydrochloric acid [8, 33, 35-37]. Next, isolated bacteria were inoculated in $10.0 \mathrm{ml}$ of handmade enrichment culture medium in culture tubes. When microbial growth occurred, the extent of the growth was determined by turbidity monitoring. After that the suspension of the microorganisms was rubbed on a $\mathrm{CaCO}_{3}$ agar plate which contained 2.2\% D-glucose, $1.0 \%$ ethanol, $1.0 \%$ yeast extract, $0.7 \% \mathrm{CaCO}_{3}$ and $1.2 \%$ agar $[36,37]$. Asaia colonies were experimentally identified by the morphological properties

Table 1 Anopheles spp. studied, their collection sites, number of the mosquitoes and the prevalence of Asaia in their midguts

\begin{tabular}{lllll}
\hline Species & Bandar-Abbas & Chabahar & Mazandaran & Kazerun \\
\hline An. stephensi & $38 / 50(70 \%)$ & $43 / 50(86 \%)$ & 0 & 0 \\
An. maculipennis & 0 & 0 & $7 / 10(70 \%)$ & 0 \\
An. superpictus & 0 & 0 & 0 & $9 / 14(64 \%)$ \\
An. fluviatilis & 0 & 0 & 0 & $7 / 16(43 \%)$ \\
An. dthali & $8 / 11(73 \%)$ & 0 & 0 & 0 \\
\hline
\end{tabular}

and formation of carbonate dissolution haloes in agar plates (Fig. 1). Colonies which were capable of clearing the $\mathrm{CaCO}_{3}$ were selected and isolated to perform more experiments and characterization. The isolates were maintained on agar slants of AG medium which contained $0.1 \%$ D-glucose, $1.5 \%$ glycerol, $0.5 \%$ peptone, $0.5 \%$ yeast extract, $0.2 \%$ malt extract, $0.7 \% \mathrm{CaCO}_{3}$ and $1.5 \%$ agar [36].

\section{Morphological, biochemical and physiological characterization}

Gram stain was used to study the morphological characteristics of bacteria. The presence of catalase was tested by adding a few drops of $3.0 \%$ hydrogen peroxide solution on the bacterial colonies. Assimilation of ammoniacal nitrogen was examined by testing the growth of isolates at $30{ }^{\circ} \mathrm{C}$ for 5 days on a medium which contained 3.0\% D-glucose, $0.1 \%\left(\mathrm{NH}_{4}\right)_{2} \mathrm{SO}_{4}, 0.01 \% \mathrm{~K}_{2} \mathrm{HPO}_{4}, 0.09 \% \mathrm{KH}_{2} \mathrm{PO}_{4}, 0.025 \%$ $\mathrm{MgSO}_{4} \cdot 7 \mathrm{H}_{2} \mathrm{O}, 0.0005 \% \mathrm{FeCl}_{3} \cdot 6 \mathrm{H}_{2} \mathrm{O}$ and its $\mathrm{pH}$ was adjusted to 4.0 and 7.0 separately [36]. In addition, growth ability was tested in AG-medium without $\mathrm{CaCO}_{3}$ and agar as basal medium which contained various concentrations of acetic acid up to $0.35 \%$ at $30{ }^{\circ} \mathrm{C}$ for five days. Acid production from sugars was tested by the method of Asai et al. [37].

\section{DNA extraction from bacterial isolates and amplification of 165 rRNA gene}

The DNA of bacterial colonies was extracted with a Cinna Pure DNA kit according to the manufacturer's instruction (Cinna Gen, Tehran, Iran). Specific forward and reverse primers were designed based on the specific $16 S$ rRNA gene fragments of Asaia bacteria using the Gene Runner software (version 5.0.59) as follows: 16sF (5'-TGG CGG ACG GGT GAG TAT C-3'), 16sR (5'-AGT TGG TTT GAC CCG AAG CC-3') based on the LT838398.1 GenBank accession number and Asafor (5'-GCG CGT AGG CGG TTT ACA C-3') and Asarev (5'-AGC GTC AGT AAT GAG CCA GGT T-3') were used based on our previous study [2]. 16sF-16sR and

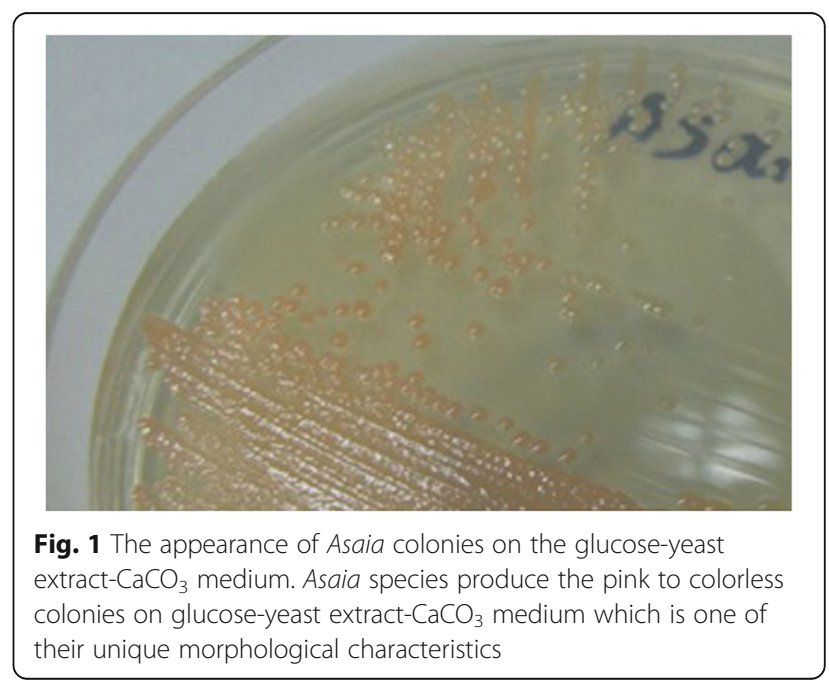


Asafor-Asarev primer pairs were used to amplify the 1370 bp and 180 bp fragments, respectively. Reaction mixtures were prepared with a final volume of $25 \mu \mathrm{l}$ using 1 unit of Dream Taq DNA polymerase (Fermentas, Waltham, USA), $0.25 \mathrm{mM}$ dNTPs, $1 \times$ Taq polymerase buffer, $0.4 \mu \mathrm{m}$ of each primer, and $20 \mathrm{ng}$ of the extracted DNA as template. Reactions were performed at $94{ }^{\circ} \mathrm{C}$ for $5 \mathrm{~min}$ and cycled 35 times through a protocol of $30 \mathrm{~s}$ at $94{ }^{\circ} \mathrm{C}, 30 \mathrm{~s}$ at $60^{\circ} \mathrm{C}$, and $100 \mathrm{~s}$ at $72{ }^{\circ} \mathrm{C}$. Finally, the reactions were maintained at $72{ }^{\circ} \mathrm{C}$ for $10 \mathrm{~min}$. Amplicon size was confirmed by agarose gel electrophoresis on $1 \%$ agarose gel. Staining was done with ethidium bromide and amplicons were visualized by an UV trans-illuminator.

\section{Cloning}

Amplified fragments were purified by the Accu Prep ${ }^{\circ}$ Gel Purification Kit according to the manufacturer's instruction (Bioneer Corporation, Seoul, Korea) and PCR products with the expected size were cloned into the pDrive TA cloning vector (Qiagen, Hilden, Germany).

\section{Sequencing}

The TA-cloned inserted sequences (six samples) were sequenced by the Millegene Company (Labege, France). Sequences were further analyzed for confirmation using the nucleotide BLAST (http://blast.ncbi.nlm.nih.gov/Blast.cgi) and those were submitted to GenBank (Table 2).

\section{Phylogenetic analysis}

In the next step, these six sequences were aligned using the MEGA6.0 software and Clustal X program with the available sequences representative of Asaia krungthepensis, Asaia bogorensis, Asaia platycodi, Asaia siamensis, Asaia lannaensis, Asaia prunellae, Asaia spathodeae and Asaia astilbes for genetic linkage analysis. Additionally, three species of the family Acetobacteraceae including Neoasaia chiangmaiensis, Gluconacetobacter takamatsuzukensis and Acetobacter aceti were selected as outgroup taxa. Phylogenetic trees were constructed using the neighbour-joining (NJ) method. The NJ analysis was performed using the

Table $\mathbf{2}$ Information about the isolated bacteria: colony codes of the isolated Asaia bacteria, Anopheles spp. from which bacteria were isolated, their collection sites and the accession numbers of the 16S rRNA gene sequence of the isolated Asaia species

\begin{tabular}{llll}
\hline Colony code & Anopheles spp. & Collection site & GenBank ID \\
\hline Colony13 & An .stephensi & Bandar-Abbas & KU529464 \\
Colony31 & An .stephensi & Chabahar & KU529465 \\
Colony33 & An. maculipennis & Mazandaran & KU529466 \\
colony41 & An. superpictus & Kazerun & KU529467 \\
colony57 & An. fluviatilis & Kazerun & KU529468 \\
colony95 & An. dthali & Bandar-Abbas & KU529469 \\
\hline
\end{tabular}

Tamura-Nei model with MEGA6.0 software [38]. The statistical robustness of the clusters was evaluated by bootstrap analysis after 1000 replications.

\section{Results}

As indicated in Table 1, Asaia bacterium was isolated with various prevalence from the field-collected Anopheles species from different regions of Iran. All the isolates were gram-negative, coccobacilli-shaped and strictly aerobic (require a shaking incubator) and their size ranges were $0.4-1.0 \times 0.8-2.0 \mu \mathrm{m}$. Isolates had swarming when those were cultured and streaked on the agar medium. Colonies were pink to yellowish and white, smooth, glossy which had been marked by a full margin on glucose-yeast extract- $\mathrm{CaCO}_{3}$ agar plates (Fig. 1). Good growth occurred at $\mathrm{pH} 3.0$ (titration with hydrochloric acid instead of acetic acid) and $30{ }^{\circ} \mathrm{C}$. All new isolates grew on mannitol, dulcitol, D-sorbitol, glycerol, and maltose agar, but none of them grew in the presence of ethanol (Table 3). In addition, the isolates did not produce a water-soluble dark pigment on the glucose-yeast extract- $\mathrm{CaCO}_{3}$ medium. Acetic acid allowed a little growth at $0.3 \%$ but at $0.35 \%$, growth was inhibited completely. Adequate growth was achieved by the use of D-glucose and ammonium sulfate as the sole sources of carbon and nitrogen on the vitamin-free medium.

As mentioned above, for molecular characterization and confirmation, we designed two sets of Asaia $16 \mathrm{~S}$ rRNA gene-specific primers. After DNA extraction of the isolated strains, PCR was performed with two sets of primers separately. Following the agarose gel electrophoresis, the 1370 bp and 180 bp specific amplicons of Asaia 16S rRNA gene were observed (Fig. 2). PCR analysis confirmed the presence of Asaia spp. in nearly 70\% of the different Anopheles specimens from distinct regions of Iran (Table 3).

These amplicons were recovered from agarose gel, TA-cloned and sequenced. Analysis of these sequences with nucleotide BLAST revealed that they were related to the $16 S$ rRNA gene of Asaia.

Among these sequences, six were submitted to the GenBank database with the accession numbers KU529464-KU529469. The details of each sequence such as geographical sources and species of the Anopheles are presented in Table 2.

In the next step, these six sequences were aligned using the MEGA6.0 software and Clustal X program with the available sequences of different species of Asaia in the GenBank database. The resulting dataset of 1300 nucleotides was used to infer the genetic relationships of the under study samples using a phylogenetic approach based on the NJ method. The constructed phylogenetic tree showed that our isolated samples were not completely similar and located in different clusters. Among them, Asaia isolates from $A n$. stephensi (Chabahar), An. maculipenis (Mazandaran) and 
Table 3 Distinctive features of the genus Asaia and other acetic acid bacteria genera [35, 42] applied for identification of Asaia within Anopheles species

\begin{tabular}{|c|c|c|c|}
\hline Feature & Asaia & Acetobacter & Gluconobacter \\
\hline Assimilation of ammonium sulfateon glucose medium & + & $+\mathrm{W}$ & - \\
\hline Acetic acid production on ethanol- $\mathrm{CaCO}_{3}$ agar & - or $+w$ & + & + \\
\hline \multicolumn{4}{|l|}{ Acid production from } \\
\hline D-mannitol & - or + & - or $+w$ & + \\
\hline D-sorbitol & - or + & - & + \\
\hline Dulcitol & + & - & - \\
\hline Glycerol & + & - & + \\
\hline Ethanol & - or $+w$ & + & + \\
\hline Maltose & + & - & - \\
\hline
\end{tabular}

Key: w, weak reaction; +, ability to use substrate; -, inability to use substrate

An. dthali (Bandar-Abbas) clustered with known Asaia spp. and revealed a close relationship with Asaia krungthepensis. Moreover, it was interesting that Asaia isolates from $A n$. superpictus (Kazerun), An. stephensi (Bandar-Abbas) and An. fluviatilis (Kazerun) clustered separately from all the other samples (Fig. 3).

\section{Discussion}

Paratransgenesis is a novel approach which has been introduced by the scientific community as an effective and promising method for controlling the vector-borne diseases such as malaria in recent years [39-41]. Among the several candidates which have been presented for

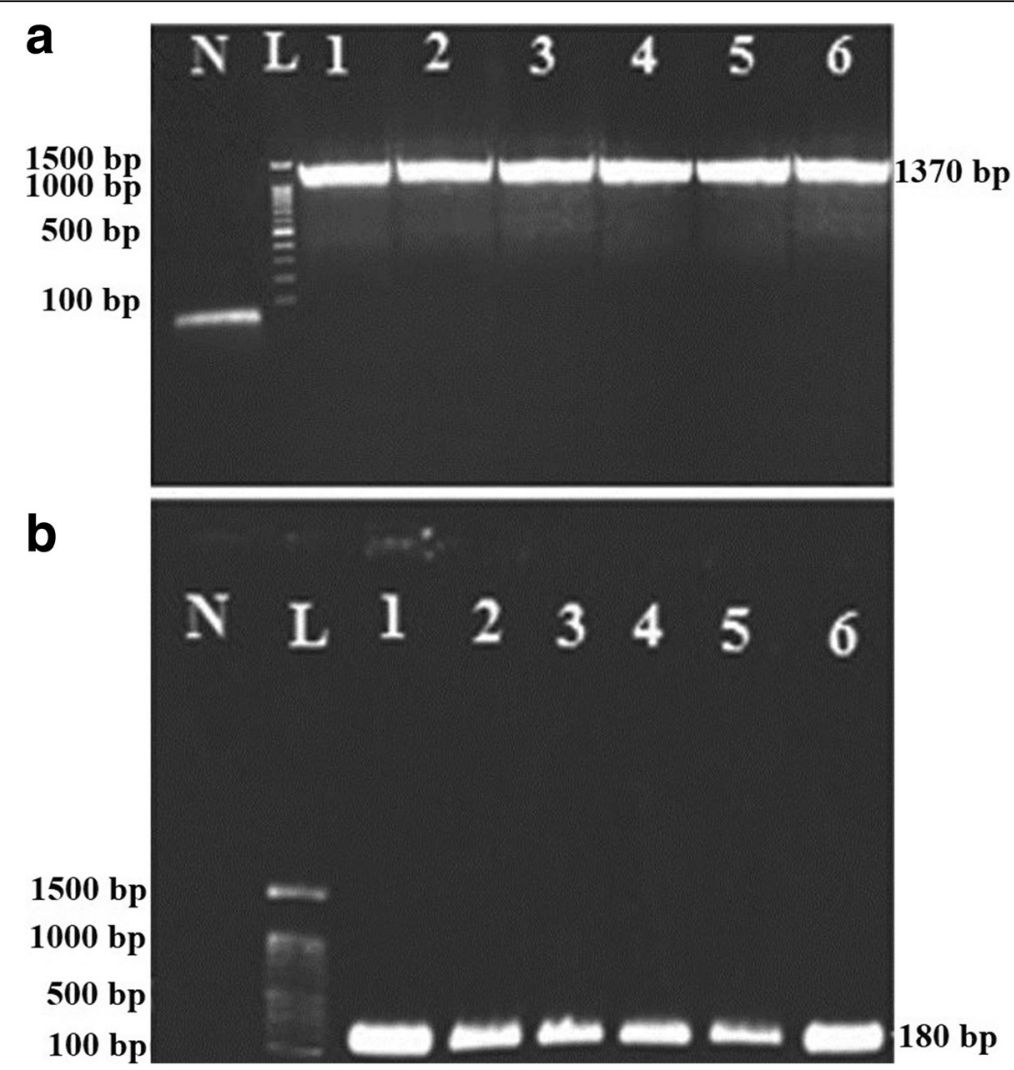

Fig. 2 Agarose gel electrophoresis of the 165 rRNA gene amplicons of Asaia sp. Electrophoresis of the $1370 \mathrm{bp}$ (a) and $180 \mathrm{bp}$ (b) amplicons which correspond to the general and specific amplicons of 16S rRNA in the genus Asaia. Lane N: negative control; Lane L: DNA marker (100-1500 bp); Lane 1: Asaia bacterium from An stephensi (Bandar-Abbas); Lane 2: Asaia bacterium from An .stephensi (Chabahar); Lane 3: Asaia bacterium from An. maculipennis (Mazandaran); Lane 4: Asaia bacterium from An. superpictus (Kazerun); Lane 5: Asaia bacterium from An. fluviatilis (Kazerun); Lane 6: Asaia bacterium from An. dthali (Bandar-Abbas) 


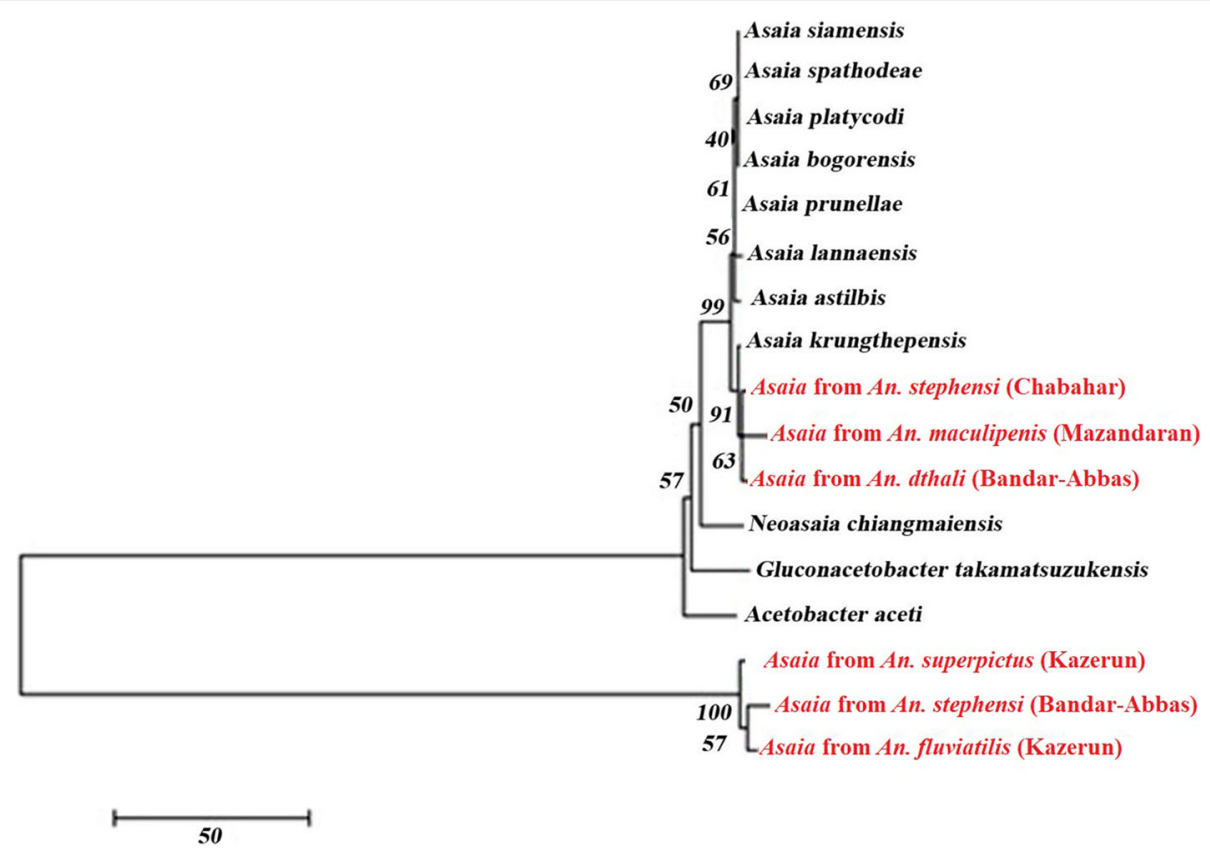

Fig. 3 Evolutionary analysis of the isolated bacteria. Phylogenetic tree created with MEGA6.0 software and ClustalX program based on 165 rRNA gene sequences. The neighbor-joining method was used for evolution relationship analysis and associated taxa were clustered together in the bootstrap test (1000 replicates)

combating malaria, Asaia is at the focus of considerations due to its specific features such as horizontal and vertical transmission and moving through the hemolymph inside the mosquito's body towards different organs. In the present study, Asaia sp. was isolated from the midgut of different Anopheles mosquitoes using the selected medium to provide the basic element for developing a robust tool against malaria.

A variety of pink-colored to colorless colonies which are observed in frequent culturing are the probable marker of growth for this bacterium [36]. Asaia is the only genus of the family Acetobacteraceae that assimilates ammonium sulfate on glucose medium. Species of this genus are not fast-growing on ethanol- $\mathrm{CaCO}_{3}$ agar, and unlike species of the other genera, do not use ethanol [42]. However, acid production from dulcitol and maltose is helpful for differentiation between the Asaia and other genera (Table 1). In addition to morphological and biochemical characterization of Asaia in this study, the isolated strains were confirmed with specific primers for the $16 \mathrm{~S}$ rRNA gene.

Sequence analysis of the $16 \mathrm{~S}$ ribosomal gene confirmed that all of these strains belonged to the genus of Asaia, but because the $16 \mathrm{~S}$ rRNA gene had high similarity among different species of this genus, the current molecular method could not differentiate these species. Regarding the fact that there is no record on preference of using a specific species of Asaia for paratransgenesis, it is necessary to evaluate their efficacy and compare the level of unique features of each species within this genus to select the best one for future paratransgenesis studies. Therefore, the biochemical tests carried out in the present study can be used to differentiate some species of the genus Asaia. For instance, unlike other species that do not grow on maltose, only this bacterium has the ability to grow in a maltose-containing environment [43]. Furthermore, the species Asaia bogorensis and Asaia siamensis which are not able to produce acetic acid from ethanol on the ethanol/calcium carbonate agar, instead can produce acid from dulcitol, glycerol and maltose [36, 43-45].

Sequence analysis of the $16 \mathrm{~S}$ ribosomal RNA gene of isolated strains in this study, confirmed the similarity and relationship of some of Asaia isolates which were detected in Anopheles from Mazandaran (An. maculipenis), Chabahar (An. stephensi), and Bandar-Abbas (An. dthali) with A. krungthepensis (Fig. 3). Furthermore, other Asaia samples which were isolated from Anopheles from Kazerun (An. superpictus and An. fluviatilis) and Bandar-Abbas (An .stephensi) clustered separately from the other isolated specimens in the phylogenetic tree (Fig. 3).

To the best of our knowledge, this is the first study of simultaneous isolation, identification and characterization of Asaia within a variety of Anopheles species, including An. maculipenis, An. stephensi, An. dthali, An. superpictus and An. fluviatilis from different zoogeographical and vector-borne disease-endemic areas in the world.

One of the major achievements of this study was that we could isolate Asaia from the insectary-reared colonies (An .stephensi from Chabahar and Bandar-Abbas). This 
achievement shows that Asaia can tolerate different situations and confirmed its vertical and horizontal transmission through several generations. With regard to the importance of Asaia in paratransgenesis, its isolation, identification, and characterization from various species of Anopheles would be beneficial and could be an applied step toward achieving the applying of paratransgenesis against malaria. Several studies have been performed for isolation of Asaia from different medically important vectors and this bacterium has been isolated from An. gambiae, An. stephensi, Aedes aegypti, Aedes albopictus, Culex pipiens and Culex quinquefasciatus [46-48]. This study is, however, the first report of isolation of Asaia from An. fluviatilis, An. maculipenis and An. dthali and the first report of its isolation from An. stephensi in Iran. However, to determine which species is dominant in each mosquito species and which of them are more efficient for using in paratransgenesis, it seems that developing new molecular or biochemical approaches are necessary.

\section{Conclusions}

In this study, samples for species of the genus Asaia were successfully isolated and identified from different Anopheles mosquito species with various vectorial capacities and from different vector-borne disease endemic regions. Phylogenetic analysis revealed that the position of the isolated Asaia samples is close to other known species of this genus. However, with the present data, determining the species of Asaia is not possible and there is a necessity for developing a novel, reliable method to differentiate various species within this genus. Introducing new technologies such as next generation sequencing and robust in silico approaches, are the promising points that may make it possible to find a unique biomarker for rapid and reliable differentiation of the Asaia species.

\section{Acknowledgments}

The authors gratefully acknowledge Dr Hamzeh Alipour for his assistance and coordination in field sampling. We thank all Colleagues in the Malaria and Vector Research Group (MVRG), Biotechnology Research Center (BRC), Pasteur Institute of Iran, Tehran, Iran for their technical assistance.

\section{Funding}

This work has been supported through the internal fund of MVRG by NDD and SZ.

\section{Availability of data and materials}

The sequences obtained and/or analyzed during the current study are deposited in the GenBank database under the accession numbers KU529464-KU529469

(16S rRNA gene). All other relevant data are included in the article.

\section{Authors' contributions}

NDD and AR conceived the study. All authors participated in the design of the study. AR performed the assays and wrote the first draft of the manuscript. All authors read and approved the final manuscript.
Consent for publication

Not applicable.

\section{Competing interests}

The authors declare that they have no competing interests.

\section{Publisher's Note}

Springer Nature remains neutral with regard to jurisdictional claims in published maps and institutional affiliations.

Received: 4 November 2017 Accepted: 15 June 2018 Published online: 28 June 2018

\section{References}

1. Lindh JM, Terenius O, Faye I. $16 \mathrm{~S}$ rRNA gene-based identification of midgut bacteria from field-caught Anopheles gambiae sensu lato and A. funestus mosquitoes reveals new species related to known insect symbionts. Appl Environ Microbiol. 2005:71:7217-23.

2. Djadid ND, Jazayeri H, Raz A, Favia G, Ricci I, Zakeri S. Identification of the midgut microbiota of An. stephensi and An. maculipennis for their application as a paratransgenic tool against malaria. PLoS One. 2011;6:e28484.

3. World Health Organization. World malaria report 2015. Geneva: World Health Organization; 2016

4. Capone A, Ricci I, Damiani C, Mosca M, Rossi P, Scuppa P, et al. Interactions between Asaia, Plasmodium and Anopheles: new insights into mosquito symbiosis and implications in Malaria Symbiotic Control. Parasit Vectors. 2013:6:182.

5. Wang S, Ghosh AK, Bongio N, Stebbings KA, Lampe DJ, Jacobs-Lorena M. Fighting malaria with engineered symbiotic bacteria from vector mosquitoes. Proc Natl Acad Sci USA. 2012;109:12734-9.

6. Alonso $\mathrm{PL}$, Chitnis $\mathrm{CE}$, Hall L. The science of malaria eradication. Yucatan: Keystone Symposia; 2014.

7. Control mCGV. A research agenda for malaria eradication: vector control. PLoS Med. 2011:8:e1000401.

8. Favia G, Ricci I, Damiani C, Raddadi N, Crotti E, Marzorati M, et al. Bacteria of the genus Asaia stably associate with Anopheles stephensi, an Asian malarial mosquito vector. Proc Natl Acad Sci USA. 2007;104:9047-51.

9. Isaacs AT, Li F, Jasinskiene N, Chen X, Nirmala X, Marinotti O, Vinetz JM, James AA. Engineered resistance to Plasmodium falciparum development in transgenic Anopheles stephensi. PLoS Pathog. 2011;7:e1002017.

10. Dong Y, Das S, Cirimotich C, Souza-Neto JA, McLean KJ, Dimopoulos G. Engineered Anopheles immunity to Plasmodium infection. PLoS Pathog. 2011;7:e1002458.

11. Isaacs AT, Jasinskiene N, Tretiakov M, Thiery I, Zettor A, Bourgouin C, James AA Transgenic Anopheles stephensi coexpressing single-chain antibodies resist Plasmodium falciparum development. Proc Natl Acad Sci USA. 2012;109:E1922-E30.

12. Kim W, Koo H, Richman AM, Seeley D, Vizioli J, Klocko AD, O'brochta DA. Ectopic expression of a cecropin transgene in the human malaria vector mosquito Anopheles gambiae (Diptera: Culicidae): effects on susceptibility to Plasmodium. J Med Entomol. 2004;41:447-55.

13. Meredith JM, Underhill A, McArthur CC, Eggleston P. Next-generation sitedirected transgenesis in the malaria vector mosquito Anopheles gambiae: self-docking strains expressing germline-specific phiC31 integrase. PLoS One. 2013:8:e59264

14. Nimmo D, Alphey L, Meredith J, Eggleston P. High efficiency site-specific genetic engineering of the mosquito genome. Insect Mol Biol. 2006;15:129-36.

15. Gantz VM, Jasinskiene N, Tatarenkova O, Fazekas A, Macias VM, Bier E, James AA. Highly efficient Cas9-mediated gene drive for population modification of the malaria vector mosquito Anopheles stephensi. Proc Natl Acad Sci USA. 2015:112:E6736-E43.

16. Hammond A, Galizi R, Kyrou K, Simoni A, Siniscalchi C, Katsanos D, et al. A CRISPR-Cas9 gene drive system targeting female reproduction in the malaria mosquito vector Anopheles gambiae. Nat Biotechnol. 2016;34:78.

17. Carballar-Lejarazú $R$, Jasinskiene N, James AA. Exogenous gypsy insulator sequences modulate transgene expression in the malaria vector mosquito, Anopheles stephensi. Proc Natl Acad Sci USA. 2013;110:7176-81.

18. Ren X, Hoiczyk E, Rasgon JL. Viral paratransgenesis in the malaria vector Anopheles gambiae. PLoS Pathog. 2008;4:e1000135

19. Suzuki Y, Niu G, Hughes GL, Rasgon JL. A viral over-expression system for the major malaria mosquito Anopheles gambiae. Sci Rep. 2014;4:5127.

20. Ren X, Rasgon JL. Potential for the Anopheles gambiae densonucleosis virus to act as an "evolution-proof" biopesticide. J Virol. 2010;84:7726-9. 
21. Riehle MA, Jacobs-Lorena M. Using bacteria to express and display antiparasite molecules in mosquitoes: current and future strategies. Insect Biochem Mol Biol. 2005;35:699-707.

22. Fang W, Vega-Rodríguez J, Ghosh AK, Jacobs-Lorena M, Kang A, Leger RJS. Development of transgenic fungi that kill human malaria parasites in mosquitoes. Science. 2011;331:1074-7.

23. Bisi DC, Lampe DJ. Secretion of anti-Plasmodium effector proteins from a natural Pantoea agglomerans isolate by using PelB and HlyA secretion signals. Appl Environ Microbiol. 2011;77:4669-75.

24. Ricci I, Damiani C, Scuppa P, Mosca M, Crotti E, Rossi P, et al. The yeast Wickerhamomyces anomalus (Pichia anomala) inhabits the midgut and reproductive system of the Asian malaria vector Anopheles stephensi. Environ Microbiol. 2011;13:911-21.

25. Manguin S, Ngo CT, Tainchum K, Juntarajumnong W, Chareonviriyaphap T, Michon A-L, Jumas-Bilak E. Bacterial biodiversity in midguts of Anopheles mosquitoes, malaria vectors in Southeast Asia. In: Manguin S, editor. Anopheles mosquitoes - new insights into malaria vectors. Rijeca: InTech; 2013. p. 549-76.

26. Chavshin AR, Oshaghi MA, Vatandoost H, Pourmand MR, Raeisi A, Enayati $A A$, et al. Identification of bacterial microflora in the midgut of the larvae and adult of wild caught Anopheles stephensi: a step toward finding suitable paratransgenesis candidates. Acta Trop. 2012;121:129-34.

27. Chavshin AR, Oshaghi MA, Vatandoost H, Pourmand MR, Raeisi A, Terenius O. Isolation and identification of culturable bacteria from wild Anopheles culicifacies, a first step in a paratransgenesis approach. Parasit Vectors. 2014;7:419.

28. Rani A, Sharma A, Rajagopal R, Adak T, Bhatnagar RK. Bacterial diversity analysis of larvae and adult midgut microflora using culture-dependent and culture-independent methods in lab-reared and field-collected Anopheles stephensi - an Asian malarial vector. BMC Microbiol. 2009;9:96.

29. Terenius O, Dantas de Oliveira C, Pinheiro WD, Tadei WP, James AA, Marinotti O. 16S rRNA gene sequences from bacteria associated with adult Anopheles darlingi (Diptera: Culicidae) mosquitoes. J Med Entomol. 2008;45:172-5.

30. Abdul-Ghani R, Al-Mekhlafi AM, Alabsi MS. Microbial control of malaria: biological warfare against the parasite and its vector. Acta Trop. 2012;121:71-84.

31. Damiani C, Ricci I, Crotti E, Rossi P, Rizzi A, Scuppa P, et al. Paternal transmission of symbiotic bacteria in malaria vectors. Curr Biol. 2008;18:R1087-R88.

32. Mamlouk D, Gullo M. Acetic acid bacteria: physiology and carbon sources oxidation. Indian J Microbiol. 2013;53:377-84.

33. Favia G, Ricci I, Marzorati M, Negri I, Alma A, Sacchi L, et al. Bacteria of the genus Asaia: a potential paratransgenic weapon against malaria. In: Aksoy S, editor. Transgenesis and the management of vector-borne disease. New York: Springer; 2008. p. 49-59.

34. Sofizadeh A, Edalat H, Abai MR, Hanafi-Bojd AA. Fauna and some biological characteristics of Anopheles mosquitoes (Diptera: Culicidae) in Kalaleh County, Golestan Province, northeast of Iran. Asian Pac J Trop Biomed. 2016;6:730-4.

35. Yamada Y, Katsura K, Kawasaki H, Widyastuti Y, Saono S, Seki T, et al. Asaia bogorensis gen. nov., sp. nov., an unusual acetic acid bacterium in the alpha-Proteobacteria. Int J Syst Evol Microbiol. 2000;50:823-9.

36. Asai $\mathrm{T}$, lizuka $\mathrm{H}$, Komagata $\mathrm{K}$. The flagellation and taxonomy of genera Gluconobacter and Acetobacter with reference to the existence of intermediate strains. J Gen Appl Microbiol. 1964;10:95-126.

37. Tamura K, Stecher G, Peterson D, Filipski A, Kumar S. MEGA6: molecular evolutionary genetics analysis version 6.0. Mol Biol Evol. 2013;30:2725-9.

38. Ramalho-Ortigão M, Coutinho-Abreu IV. Transgenesis, paratransgenesis and transmission blocking vaccines to prevent insect-borne diseases. In: Larramendy ML, editor. Integrated pest management and pest control: Current and future tactics. Rijeca: InTech; 2012. p. 581-612.

39. Coutinho-Abreu IV, Zhu KY, Ramalho-Ortigao M. Transgenesis and paratransgenesis to control insect-borne diseases: current status and future challenges. Parasitol Int. 2010;59:1-8.

40. Hurwitz I, Fieck A, Read A, Hillesland H, Klein N, Kang A, Durvasula R. Paratransgenic control of vector-borne diseases. Int J Biol Sci. 2011;7:1334.

41. Sharafi S, Rasooli I, Beheshti-Maal K. Isolation, characterization and optimization of indigenous acetic acid bacteria and evaluation of their preservation methods. Iran J Microbiol. 2010;2:38.

42. Yukphan P, Potacharoen W, Tanasupawat S, Tanticharoen M, Yamada Y, Asaia krungthepensis sp. nov., an acetic acid bacterium in the aProteobacteria. Int J Syst Evol Microbiol. 2004;54:313-6.

43. Malimas T, Yukphan P, Takahashi M, Kaneyasu M, Potacharoen W, Tanasupawat $\mathrm{S}$, et al. Asaia lannaensis sp. nov., a new acetic acid bacterium in the Alphaproteobacteria. Biosci Biotechnol Biochem. 2008; 72:666-71.
44. Katsura K, Kawasaki H, Potacharoen W, Saono S, Seki T, Yamada Y, et al. Asaia siamensis sp. nov., an acetic acid bacterium in the alpha-proteobacteria. Int J Syst Evol Microbiol. 2001;51:559-63.

45. Chouaia B, Rossi P, Montagna M, Ricci I, Crotti E, Damiani C, et al. Molecular evidence for multiple infections as revealed by typing of Asaia bacterial symbionts of four mosquito species. Appl Environ Microbiol. 2010;76:7444-50.

46. Crotti E, Damiani C, Pajoro M, Gonella E, Rizzi A, Ricci I, et al. Asaia, a versatile acetic acid bacterial symbiont, capable of cross-colonizing insects of phylogenetically distant genera and orders. Environ Microbiol. 2009;11: 3252-64.

47. Damiani C, Ricci I, Crotti E, Rossi P, Rizzi A, Scuppa P, et al. Mosquito-bacteria symbiosis: the case of Anopheles gambiae and Asaia. Microb Ecol. 2010;60:644-54.

48. De Freece C, Damiani C, Valzano M, D'amelio S, Cappelli A, Ricci I, Favia G. Detection and isolation of the a-proteobacterium Asaia in Culex mosquitoes. Med Vet Entomol. 2014;28:438-42.

\section{Ready to submit your research? Choose BMC and benefit from:}

- fast, convenient online submission

- thorough peer review by experienced researchers in your field

- rapid publication on acceptance

- support for research data, including large and complex data types

- gold Open Access which fosters wider collaboration and increased citations

- maximum visibility for your research: over $100 \mathrm{M}$ website views per year

At BMC, research is always in progress.

Learn more biomedcentral.com/submissions 